\title{
Decreased Expression of SATB2 Associates with Tumor Growth and Predicts Worse Outcome in Patients with Clear Cell Renal Cell Carcinoma
}

\author{
AGNIESZKA SLIWINSKA-JEWSIEWICKA ${ }^{1 *}$, ANNA E. KOWALCZYK ${ }^{1 *}$, \\ BARTLOMIEJ E. KRAZINSKI ${ }^{1}$, JANUSZ GODLEWSKI ${ }^{1}$, PRZEMYSLAW KWIATKOWSKI ${ }^{1}$, \\ JOLANTA KIEWISZ ${ }^{1}$, JEDRZEJ GRZEGRZOLKA ${ }^{2}$, PIOTR DZIEGIEL ${ }^{2,3}$ and ZBIGNIEW KMIEC ${ }^{1,4}$ \\ ${ }^{I}$ Department of Human Histology and Embryology, School of Medicine, \\ Collegium Medicum, University of Warmia and Mazury in Olsztyn, Olsztyn, Poland; \\ ${ }^{2}$ Department of Histology and Embryology, Wroclaw Medical University, Wroclaw, Poland; \\ ${ }^{3}$ Department of Physiotherapy, Wroclaw University School of Physical Education, Wroclaw, Poland; \\ ${ }^{4}$ Department of Histology, Medical University of Gdansk, Gdansk, Poland
}

\begin{abstract}
Background/Aim: SATB2 (special AT-rich sequence-binding protein 2) is a DNA-binding protein that is involved in transcriptional regulation and chromatin remodeling. SATB2 protein has been described as a promising novel marker in several human cancers. Patients and Methods: This study compared SATB2 expression in tumor and matched unchanged renal tissues collected from 57 patients with clear cell renal cell carcinoma (ccRCC). SATB2 mRNA levels were determined by quantitative polymerase chain reaction, while SATB2 protein expression was estimated by immunohistochemistry. Moreover, the associations between SATB2 expression in ccRCC samples and clinicopathological and survival data of the patients were investigated. Results: The mRNA level of SATB2 was lower in tumor tissues than in samples of corresponding unchanged kidney. Although the average immunoreactivity of SATB2 protein did not differ significantly between cancer cells and epithelial cells of proximal convoluted tubules, the decreased SATB2 expression in tumor specimens inversely correlated with the size of primary tumor and predicted worse patients' outcome. Conclusion: The results of the presented study suggest the tumor-suppressing function of
\end{abstract}

*These Authors contributed equally to this study.

Correspondence to: Dr. Anna Kowalczyk, Department of Human Histology and Embryology, Faculty of Medicine, University of Warmia and Mazury, 30 Warszawska Str., 10-082 Olsztyn, Poland. Tel/Fax: +48 895245306, e-mail: a.kowalczyk@uwm.edu.pl

Key Words: SATB2 expression, clear cell renal cell carcinoma, clinicopathological parameters, survival, qPCR, IHC.
SATB2 and that the expression level of this protein can be considered a potential prognostic factor in ccRCC.

Renal cell carcinoma (RCC) is diagnosed in more than 200,000 individuals worldwide each year, accounting for approximately $2 \%$ of all cancers (1). RCC is a clinicopathologically-heterogeneous disease and comprises of several histological subtypes that are phenotypically and genetically different. Clear cell renal cell carcinoma (ccRCC) is the most common subtype of RCC, representing approximately $70-80 \%$ of all RCC cases (2). ccRCC carries a worse prognosis than the other histological variants, such as papillary and chromophobe RCC (3). It seems that this is the result of the highly invasive character of ccRCC and that micro-metastases can even develop during early stages of disease. Moreover, ccRCC is highly resistant to radiation, chemotherapy, and targeted therapy (4). The five-year survival rate of ccRCC is approximately $5-15 \%$ (5). It is thought that initiation and progression of RCC are a consequence of the accumulation of genetic alterations involving numerous various genes $(4,6)$, therefore, identification and investigations of differentially expressed genes are needed to test their usefulness as molecular markers and therapeutic targets.

Special AT-rich sequence-binding protein-2 (SATB2) gene encodes a nuclear matrix associated protein, which is a transcription factor and epigenetic regulator involved in chromatin remodeling and regulation of gene expression (7, 8). SATB2 participates in growth and developmental processes. It controls the activity of transcription factors that regulate craniofacial development as well as osteoblasts' and cortical neurons differentiation $(9,10)$. This protein also modulates immunoglobulin gene expression (11). Moreover, 
few studies have indicated that SATB2 may play an important role in the development and progression of some types of cancers (12-20), and the level of its expression can be used as a prognostic factor, although the prognostic value of SATB2 expression depends on cancer type $(12,13,16$ 19). Furthermore, the results of investigations are controversial. Some studies showed higher SATB2 expression in tumor tissues compared to non-cancerous specimens and that SATB2 functions as an oncogene (12$15)$, while other reports revealed a tumor suppressive role of SATB2 and reduced amount of this protein in cancer tissues (16-20). Thus, the level of SATB2 expression and its function seems to be cancer-type specific.

So far, the prognostic significance of SATB2 expression in ccRCC was investigated only in one study (21), whose authors, due to the small number of patients included, suggested the need for further studies to confirm their findings. Therefore, the main purpose of our research was to compare $S A T B 2$ gene expression in samples of the ccRCC tissue and matched unchanged kidney and analyze correlations between the expression level of $S A T B 2$ and clinicopathological features, as well as overall survival (OS) in the cohort of Polish patients. Quantitative real-time polymerase chain reaction (qPCR) was used to assess SATB2 mRNA levels, while an immunohistochemical (IHC) method was applied to determine the expression of SATB2 protein in the tested samples.

\section{Materials and Methods}

Ethics. The present study was carried out in accordance with the ethical standards, and approved by the Bioethics Committee of the University of Warmia and Mazury in Olsztyn (decision no. 22/2010 and 4/2010). Written informed consent regarding the participation in the study and use of tissue was obtained from each patient.

Patients and the collection of tissue samples. The specimens were collected at the Hospital of the Ministry of Internal Affairs and Administration in Olsztyn (Poland) from 2010 to 2014. The study included 57 patients with ccRCC (28 men and 29 women; aged $64.05 \pm 10.93$ years, mean $\pm \mathrm{SD}$; range $=27-83$ years). None of the patients had a history of other tumor or suffered from other serious disease. The demographic and clinical characteristics as well as survival data of all patients were gathered. Median follow-up time was 40.8 months.

Two types of samples from each patient subjected to radical nephrectomy were obtained immediately after surgical resection: (i) ccRCC tissue, and (ii) matched macroscopically unchanged renal cortex tissue from a distant part of the resected kidney. Tissue samples for qPCR analysis were frozen in liquid nitrogen and stored at $-80^{\circ} \mathrm{C}$, while specimens for routine histological and immunohistochemical evaluation were fixed in neutral $4 \%$ bufferedformaldehyde and further processed into paraffin blocks. The tumor stage was characterized by a pathologist according to the TNM system (AJCC Cancer Staging; American Joint Committee on Cancer) (22). The degree of tumor malignancy was determined using the Fuhrman nuclear grading system (23).
Total RNA extraction, reverse transcription and $q P C R$. Total RNA was extracted from all studied tissues using a Total RNA Prep Plus kit (A\&A Biotechnology, Gdynia, Poland), according to the procedure provided. Isolated RNA was quantified with spectrophotometry (NanoDrop 1000, NanoDrop products, Wilmington, DE, USA). Reverse transcription was carried out using the High-Capacity cDNA Reverse Transcription Kit (Life Technologies - Applied Biosystems, Foster City, CA, USA). Reactions were performed according to the manufacturer's instructions, and resulting complementary DNAs (cDNAs) were diluted 6-fold with nuclease-free water and stored at $-20^{\circ} \mathrm{C}$ to be used as templates in qPCR analysis.

Quantification of SATB2 gene expression was carried out using ABI 7500/7500 Fast Real-Time PCR System (Life Technologies Applied Biosystems, Foster City, CA, USA). TATA box binding protein $(T B P)$ and peptidylprolylisomerase A (PPIA) genes were applied as an internal control to normalize the transcript levels of $S A T B 2$. The levels of SATB2, TBP and PPIA cDNAs in collected isolates were determined using TaqMan ${ }^{\circledR}$ Fast Advanced Master Mix and a respective TaqMan ${ }^{\circledR}$ Gene Expression Assay (for $S A T B 2$ : Hs00392652_m1, TBP: Hs00427620_m1 and PPIA: Hs99999904_m1; all: Life Technologies - Applied Biosystems, Foster City, CA, USA) according to the manufacturer's instructions and using the following conditions: polymerase activation for $20 \mathrm{sec}$ at $95^{\circ} \mathrm{C}$, followed by 40 cycles of denaturation at $95^{\circ} \mathrm{C}$ for $3 \mathrm{sec}$ and annealing/extension at $60^{\circ} \mathrm{C}$ for $30 \mathrm{sec}$. The $\Delta \Delta \mathrm{Ct}$ method (24) was applied to determine the fold differences in $S A T B 2$ expression between the matched samples of ccRCC and unchanged kidney. Fold increase above $1\left(2^{-\Delta \Delta C t}>1\right)$ indicated SATB2 overexpression in ccRCC tissue, and fold decrease under $1(2-\Delta \Delta \mathrm{Ct}<1)$ indicated SATB2 down-regulation.

Immunohistochemistry and evaluation of immunoreactivity. SATB2 immunostaining in ccRCC and unchanged renal tissues was performed according to the previously described method (25) on 4 $\mu \mathrm{m}$-thick paraffin sections using the Autostainer Link48 (DakoCytomation, Glostrup, Denmark). Rabbit monoclonal primary antibody directed against SATB2 (1:100, Anti-SATB2 antibody EPNCIR130A, ab92446, Abcam, Cambridge, UK) was applied, while the negative controls were performed by omitting the primary antibody.

The SATB2 immunostained sections were evaluated using Olympus BX53 light microscope (Olympus, Tokyo, Japan) by a pathologist in a blinded manner regarding the clinicopathological data of the patients. The scoring system for nuclear SATB2 immunoreactivity was based on the percentage of SATB2-positive ccRCC cells or proximal convoluted tubules (PCTs) epithelial cells ( 0 , absence of staining; 1 , when $1-10 \%$ cells were immunoreactive; $2,11-50 \% ; 3,51-80 \%$ and $4,>80 \%)$.

Based on median expression values, ccRCC cases which showed expression scores $\leq 1$ were regarded as having 'low' expression, whereas scores $>1$ were regarded as 'high' SATB2 expression.

Statistical analysis. Statistical analyses were carried out using Prism software (v. 6.04; GraphPad, La Jolla, CA, USA). The differences in SATB2 mRNA and protein levels between matched ccRCC and unchanged kidney tissues were examined by the Wilcoxon matchedpairs test. The correlations between the clinicopathological characteristics and $S A T B 2$ gene expression were analyzed by the Fisher's exact test or Spearman correlation. The log-rank test was 

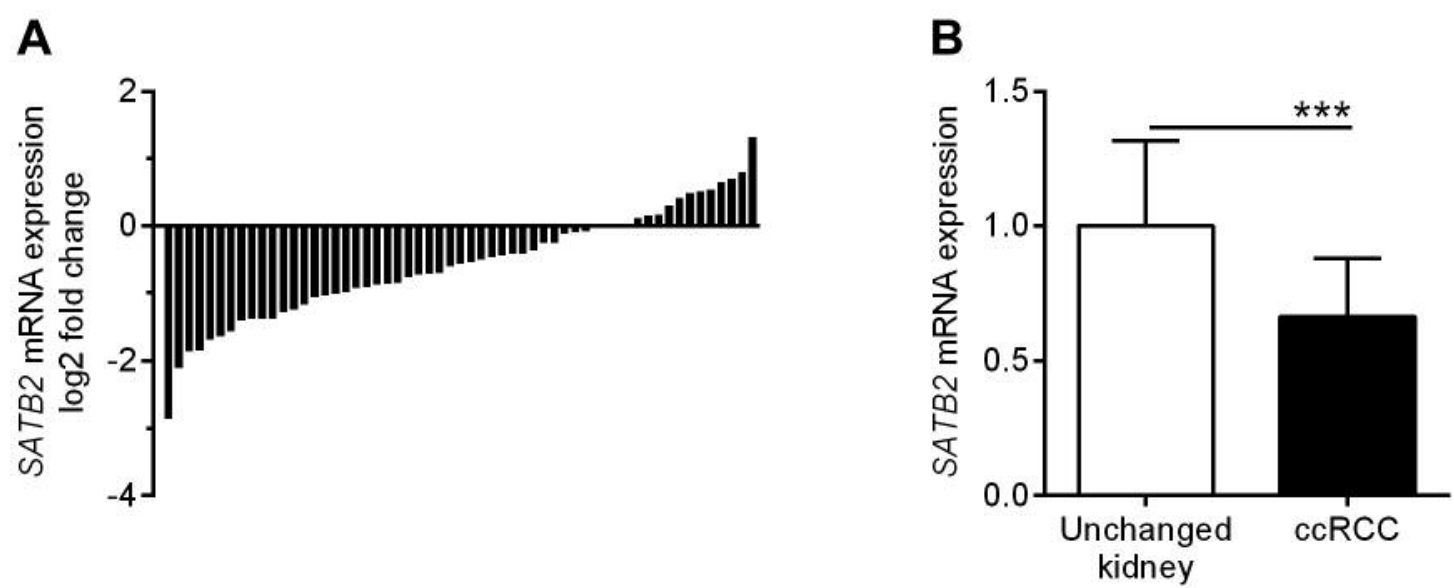

Figure 1. SATB2 mRNA levels in the tumor and unchanged kidney tissues of clear cell renal cell carcinoma (ccRCC) patients ( $n=57)$ as determined by quantitative polymerase chain reaction. (A) SATB2 mRNA levels in tumors of individual ccRCC patients are shown in relation to the SATB2 $m R N A$ content in matched unchanged renal tissues. (B) The average expression of SATB2 mRNA (mean $\pm S E M)$ in ccRCC tissues is shown in relation to the value obtained for unchanged kidney tissues (1.0); ***p<0.0001.

used to evaluate the statistical significance of differences in OS between groups of patients. Survival curves were plotted using Kaplan-Meier method. In all performed analyses, the results were considered statistically significant at $p<0.05$.

\section{Results}

SATB2 mRNA expression is decreased in ccRCC. SATB2 mRNA was found in all studied tissue samples of ccRCC patients. The average expression of SATB2 mRNA was significantly decreased in ccRCC when compared to unchanged kidney tissues $(0.67 \pm 0.21$ vs. $1.00 \pm 0.32$, respectively, $p<0.0001$; Figure 1). Among the 57 tumor specimens tested, the relative $S A T B 2$ mRNA level (ccRCC $v s$. matching unchanged kidney tissues) was decreased in 43 $(75.4 \%)$ tumors and increased in $14(24.6 \%)$ specimens. The relative expression of $S A T B 2$ did not correlate with any of the tested clinicopathological parameters (Table I).

Heterogenous nuclear SATB2 immunohistochemical staining in ccRCC tissues. SATB2 immunoreactivity was observed mainly in the nuclei of ccRCC cells and epithelial cells of PCTs and only several specimens revealed a weak immunostaining of SATB2 in the cytoplasm of examined cells (Figure 2). Among 57 ccRCC specimens tested, nuclear immunoreactivity of the SATB2 protein was low in 33 $(57.9 \%)$ and high in $24(42.1 \%)$ cases. (Table I). The average levels of nuclear SATB2 immunoreactivity did not differ significantly between ccRCC and PCT epithelial cells (1.26 $\pm 0.18 v s .1 .59 \pm 0.08$, respectively, $p=0.1178$; Figure 3 ). However, the negative correlation was found between the level of the SATB2 immunoreactivity and primary tumor size ( $\mathrm{r}=-0.3413, p=0.0094$; Table I).
OS of patients is associated with the SATB2 immunoreactivity level in $c c R C C$. To estimate the prognostic significance of the studied gene expression, all patients were followed up for the median time of 40.8 months. During this observation period, 21/57 (36.8\%) patients deceased (Table II).

Decreased nuclear immunoreactivity of SATB2 in ccRCC specimens (hazard ratio $(\mathrm{HR})=2.89 ; p=0.0298$; Figure 4), higher Fuhrman grade $(p<0.0001)$, AJCC stage $(p=0.0019)$, and tumor size $(p=0.0114)$, presence of distant metastases $(p=0.0008)$ and invasive status of the disease $(p=0.0302)$ were found to be associated with worse patient prognosis (Table II). The SATB2 mRNA expression level did not correlate with patients' OS ( $p=0.5859$; Table II; Figure 4).

\section{Discussion}

SATB2 regulates gene expression by modulating chromatin architecture and by functioning as a transcriptional factor (79), and in this way, it is involved in a variety of important biological as well as pathological processes. In addition to its roles in development processes, especially in craniofacial morphogenesis (9), SATB2 seems to be associated with pathogenesis of some types of cancers. It was shown that SATB2 participates in pancreatic carcinogenesis inducing cellular transformation, stemness and epithelial to mesenchymal transition (EMT), and inhibition of its expression suppresses these activities (12). It was found that SATB2 promotes invasion and proliferation of human hepatocellular carcinoma cells (15), as well as chemoresistance of head and neck squamous cell carcinoma cells (14). However, the opposite results were also reported. SATB2 suppressed cell invasion, metastasis and EMT-related 
Table I. Associations between clinicopathological features of ccRCC patients and the relative mRNA expression of SATB2 gene in kidney tumor tissues or SATB2 nuclear immunoreactivity in cancer cells.

\begin{tabular}{|c|c|c|c|c|c|c|c|}
\hline \multirow[b]{2}{*}{ Parameters } & \multirow[b]{2}{*}{$\begin{array}{c}\text { Patients } \\
n\end{array}$} & \multicolumn{2}{|c|}{$\begin{array}{l}\text { SATB2 mRNA levels in tumor tissue vs. } \\
\text { normal renal tissue of ccRCC patients }\end{array}$} & \multirow[b]{2}{*}{$p$-Value ${ }^{a}$} & \multicolumn{2}{|c|}{$\begin{array}{l}\text { SATB2 nuclear immunoreactivity } \\
\text { in ccRCC cells }\end{array}$} & \multirow[b]{2}{*}{$p$-Value } \\
\hline & & $\begin{array}{c}\text { Down }(\text { ratio }<1) \\
n(\%)\end{array}$ & $\begin{array}{c}\mathrm{Up}(\mathrm{ratio}>1) \\
\mathrm{n}(\%)\end{array}$ & & $\begin{array}{l}\text { Score } 0-1 \\
\mathrm{n}(\%)\end{array}$ & $\begin{array}{l}\text { Score } 2-4 \\
\mathrm{n}(\%)\end{array}$ & \\
\hline Total & 57 & $43(75.4)$ & $14(24.6)$ & & $33(57.9)$ & $24(42.1)$ & \\
\hline \multicolumn{8}{|l|}{ Gender } \\
\hline Men & 28 & $22(78.6)$ & $6(21.4)$ & 0.7598 & $17(60.7)$ & $11(39.3)$ & 0.7901 \\
\hline Women & 29 & $21(72.4)$ & $8(27.6)$ & & $16(55.2)$ & $13(44.8)$ & \\
\hline \multicolumn{8}{|l|}{ Depth of invasion } \\
\hline $\mathrm{T} 1+\mathrm{T} 2$ & 43 & $32(74.4)$ & $11(25.6)$ & 1.0000 & $22(51.2)$ & $21(48.8)$ & 0.1183 \\
\hline $\mathrm{T} 3$ & 14 & $11(78.6)$ & $3(21.4)$ & & $11(78.6)$ & $3(21.4)$ & \\
\hline \multicolumn{8}{|l|}{ Fuhrman grade } \\
\hline $\mathrm{G} 1+\mathrm{G} 2$ & 42 & $32(76.2)$ & $10(23.8)$ & 1.0000 & $22(52.4)$ & $2047.6)$ & 0.2260 \\
\hline $\mathrm{G} 3+\mathrm{G} 4$ & 15 & $11(73.3)$ & $4(26.7)$ & & $11(73.3)$ & $4(26.7)$ & \\
\hline \multicolumn{8}{|l|}{ Distant metastases } \\
\hline Absent & 48 & $36(75.0)$ & $12(25.0)$ & 1.0000 & $27(56.3)$ & $21(43.8)$ & 0.7197 \\
\hline Present & 9 & $7(77.8)$ & $2(22.2)$ & & $6(66.7)$ & $3(33.3)$ & \\
\hline \multicolumn{8}{|l|}{ AJCC staging } \\
\hline $\mathrm{I}+\mathrm{II}$ & 37 & $27(73.0)$ & $10(27.0)$ & 0.7493 & $19(51.4)$ & $18(48.6)$ & 0.2614 \\
\hline $\mathrm{III}+\mathrm{IV}$ & 20 & $16(80.0)$ & $4(20.0)$ & & $14(70.0)$ & $6(30.0)$ & \\
\hline Quantitative parameters & & $\mathrm{r}$ & $p$-Value ${ }^{b}$ & & $\mathrm{r}$ & $p$-Value $\mathrm{b}$ & \\
\hline Age & 57 & 0.1449 & 0.2822 & & 0.1636 & 0.2239 & \\
\hline Primary tumor size & 57 & -0.1716 & 0.2017 & & -0.3413 & $0.0094^{\mathrm{c}}$ & \\
\hline
\end{tabular}

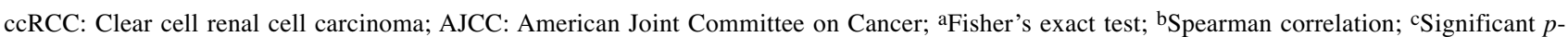
value $(<0.05)$.

proteins in non-small cell lung cancer cells (19), furthermore, it inhibited proliferation and tumor progression ability of Hep2 (laryngeal squamous cell carcinoma cell line) cells (18). Exogenous expression of SATB2 in colorectal cancer cells also suppressed cell proliferation, colony formation and in vivo tumor growth (26). These findings indicated the cancer type-specific functions of SATB2, thus, it can be expected that also $S A T B 2$ gene expression levels differ depending on the kind of cancer.

Increased expression of $S A T B 2$ gene in the tumor compared to control non-cancerous tissues was observed in pancreatic (12), breast (13), hepatocellular (15) and head and neck squamous cell (14) cancers, while its decreased expression was revealed in colorectal (26), laryngeal (18) and esophageal squamous cell (16) cancers. SATB2 is a member of the SATB family proteins and it is closely related to another protein abnormally expressed in ccRCC - SATB1 (27). To date, the evaluation of $S A T B 2$ expression in association with its prognostic value in ccRCC has been limited to one study (21). Our finding of significantly reduced $S A T B 2$ mRNA levels in ccRCC compared to matching unchanged kidney tissues is in line with the results of Guo et al. (21); however, in contrast to the mentioned authors, we did not observe the difference in SATB2 protein immunoreactivity between ccRCC and PCTs epithelial cells, although the average immunoexpression of SATB2 protein in ccRCC tended to be lower than in unchanged kidney tissue. Our observations suggest that in ccRCC, dysregulation of some mechanisms suppresses the SATB2 expression. Previous studies established that SATB2 regulation may vary by cell type (28), and microRNAs (miRNAs, miRs) and distant regulatory elements play a significant role in controlling the expression of $S A T B 2$. It was found that AS021, a short interspersed repetitive sequence and a type of retrotransposon, acts as a distal enhancer resulting in an increase of SATB2 expression (28, 29). Another regulator, Runx2, is a transcription factor that promotes $S A T B 2$ expression by blocking the miR cluster 

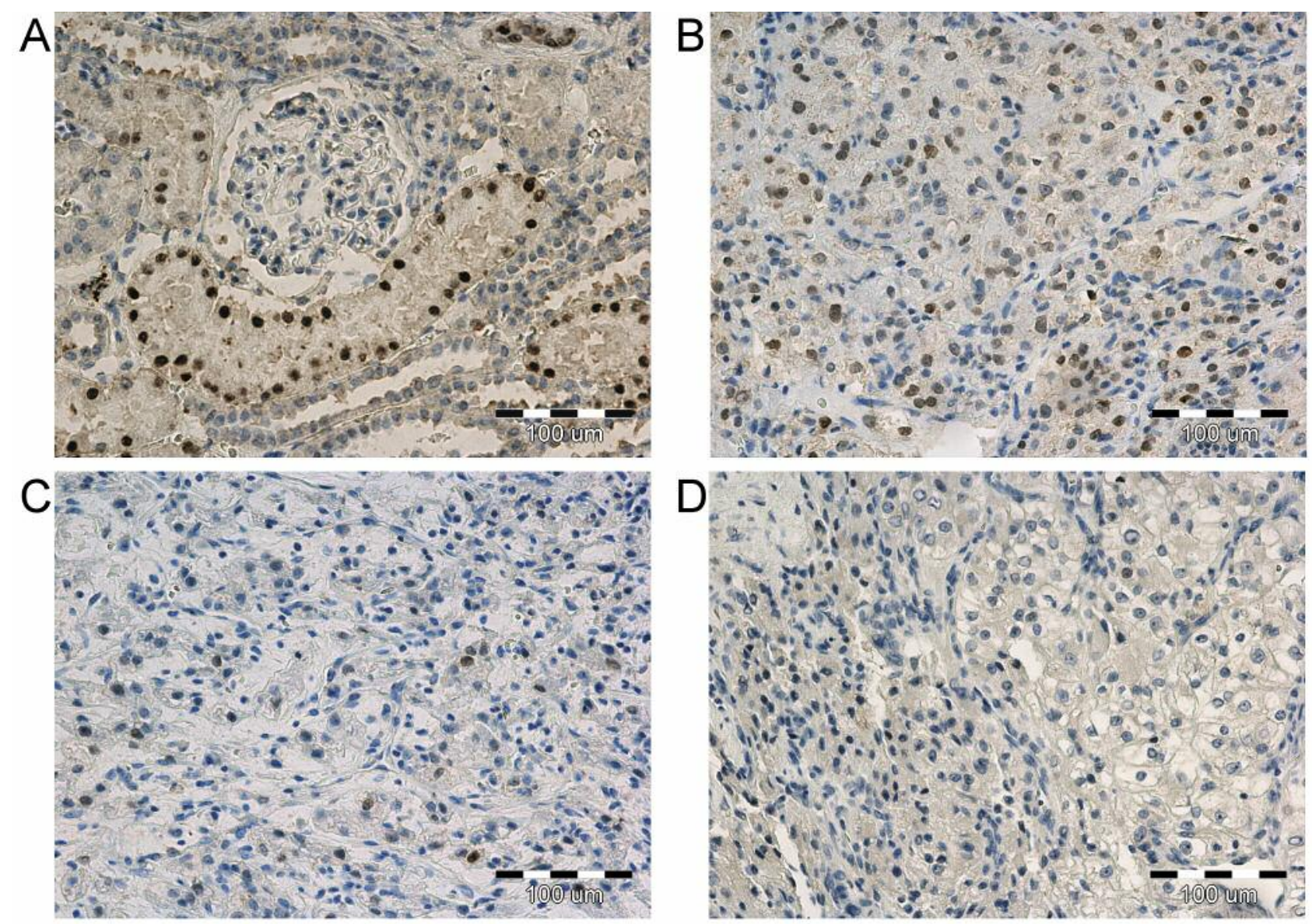

Figure 2. Evaluation of SATB2 protein expression in clear cell renal cell carcinoma and unchanged renal tissues by immunohistochemistry. (A) Intense nuclear and cytoplasmic immunohistochemical staining of SATB2 protein in the proximal tubules cells of unchanged kidney cortex, (B) dominant nuclear and low cytoplasmic SATB2 immunoreactivity in ccRCC cells, (C) low nuclear immunostaining in tumor cells. (D) Negative controls were performed by omitting the primary antibody. Magnification $\times 200$.

A

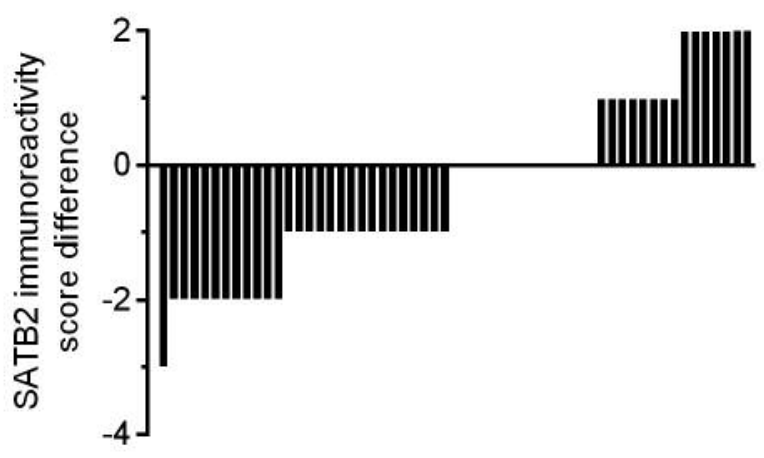

B

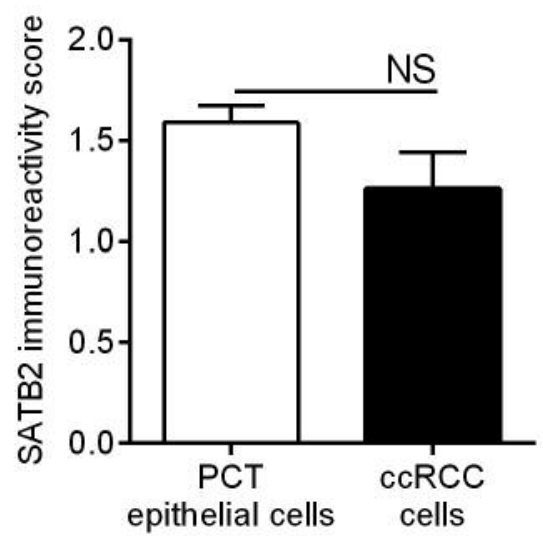

Figure 3. Nuclear expression of SATB2 protein in the tumor and unchanged kidney tissues of clear cell renal cell carcinoma (ccRCC) patients $(n=57)$ determined by immunohistochemistry. (A) The level of nuclear SATB2 immunoreactivity in tumors of individual ccRCC patients is shown in relation to the level of SATB2 immunostaining in matched unchanged renal tissues. (B) The average nuclear immunoreactivity of the SATB2 protein in epithelial cells of proximal convoluted tubules (PCT) and ccRCC cells. Bars represent mean \pm SEM. NS, Not significant. 
A

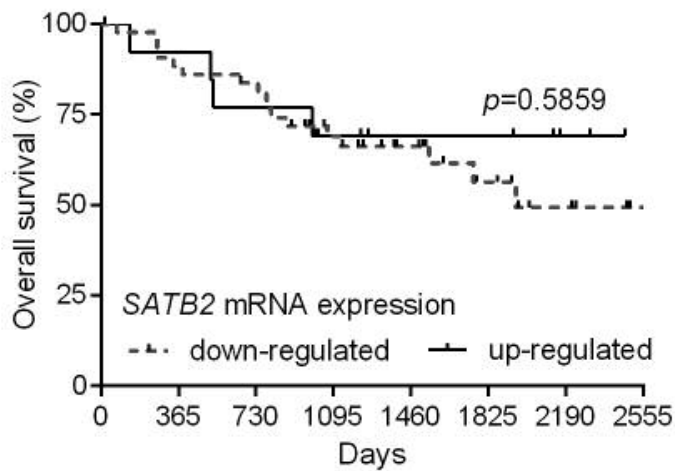

B

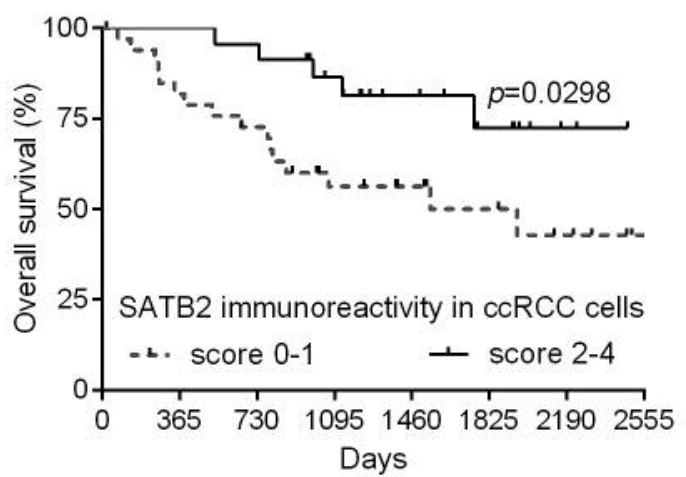

Figure 4. Kaplan-Meier survival curves of 57 clear cell renal cell carcinoma (ccRCC) patients regarding the levels of (A) SATB2 mRNA expression and (B) nuclear immunoreactivity of SATB2 protein in ccRCC tissues.

Table II. Analysis of overall survival of ccRCC patients in relation to their clinicopathological characteristics and SATB2 expression.

\begin{tabular}{|c|c|c|c|c|c|}
\hline Parameter & Deaths/Cases & Percentage $(\%)$ & HR & $95 \% \mathrm{CI}$ of $\mathrm{HR}$ & $p$-Value \\
\hline Total & $21 / 57$ & 36.8 & & & \\
\hline \multicolumn{6}{|c|}{$S A T B 2$ mRNA in ccRCC } \\
\hline Down-regulated & $17 / 43$ & 39.5 & 1.35 & \multirow{2}{*}{0.49 to 3.59} & \multirow{2}{*}{0.5859} \\
\hline Up-regulated & $4 / 14$ & 28.6 & $(1.00)$ & & \\
\hline \multicolumn{6}{|c|}{ SATB2 nuclear immunoreactivity in ccRCC } \\
\hline Score $0-1$ & $16 / 33$ & 48.5 & 2.89 & \multirow[t]{2}{*}{1.10 to 6.11} & \multirow[t]{2}{*}{$0.0298^{\mathrm{a}}$} \\
\hline Score $2-4$ & $5 / 24$ & 20.8 & $(1.00)$ & & \\
\hline \multicolumn{6}{|l|}{ Gender } \\
\hline Men & $8 / 28$ & 28.6 & 0.57 & \multirow[t]{2}{*}{0.24 to 1.34} & \multirow[t]{2}{*}{0.1995} \\
\hline Women & $13 / 29$ & 44.8 & $(1.00)$ & & \\
\hline \multicolumn{6}{|l|}{$\mathrm{T}$ status } \\
\hline $\mathrm{T} 1+\mathrm{T} 2$ & $13 / 43$ & 30.2 & 0.39 & \multirow[t]{2}{*}{0.10 to 0.89} & \multirow[t]{2}{*}{$0.0302^{\mathrm{a}}$} \\
\hline $\mathrm{T} 3$ & $8 / 14$ & 57.1 & $(1.00)$ & & \\
\hline \multicolumn{6}{|c|}{ Fuhrman nuclear grade } \\
\hline $\mathrm{G} 1+\mathrm{G} 2$ & $10 / 42$ & 23.8 & 0.17 & \multirow[t]{2}{*}{0.02 to 0.16} & \multirow[t]{2}{*}{$<0.0001^{\mathrm{a}}$} \\
\hline $\mathrm{G} 3+\mathrm{G} 4$ & $11 / 15$ & 73.3 & $(1.00)$ & & \\
\hline \multicolumn{6}{|l|}{ Distant metastases } \\
\hline Absent & $14 / 48$ & 29.2 & 0.24 & \multirow[t]{2}{*}{0.02 to 0.36} & \multirow[t]{2}{*}{$0.0008^{\mathrm{a}}$} \\
\hline Present & $7 / 9$ & 77.8 & $(1.00)$ & & \\
\hline \multicolumn{6}{|l|}{ AJCC staging } \\
\hline I+II & $9 / 37$ & 24.3 & 0.28 & \multirow[t]{2}{*}{0.08 to 0.56} & \multirow[t]{2}{*}{$0.0019^{\mathrm{a}}$} \\
\hline III+IV & $12 / 20$ & 60.0 & $(1.00)$ & & \\
\hline \multicolumn{6}{|c|}{ Tumor size group $(\mathrm{cm})$} \\
\hline$\leq 10$ & $16 / 51$ & 31.4 & 0.30 & \multirow[t]{2}{*}{0.03 to 0.64} & \multirow[t]{2}{*}{$0.0114^{\mathrm{a}}$} \\
\hline$>10$ & $5 / 6$ & 83.3 & $(1.00)$ & & \\
\hline \multicolumn{6}{|l|}{ Age group (years) } \\
\hline$<61$ & $11 / 26$ & 42.3 & 1.39 & \multirow[t]{2}{*}{0.59 to 3.30} & \multirow[t]{2}{*}{0.4497} \\
\hline$>61$ & $10 / 31$ & 32.3 & $(1.00)$ & & \\
\hline
\end{tabular}

Medium follow-up time: 40.8 months. aSignificant $p$-value $(<0.05)$. ccRCC: Clear cell renal cell carcinoma; AJCC: American Joint Committee on Cancer; HR: hazard ratio; CI: confidence interval; RQ: relative quantification.

23a-27a-24-2, which negatively regulates SATB2 $(28,30)$. Moreover, it was also found that Runx2 inhibits miRNA-31, another negative regulator of $\operatorname{SATB} 2(28,31)$. Results of some studies have indicated that miR-31 (32) and miR-182 (33) repress $S A T B 2$ expression in colorectal cancer, while miR-211 (15) negatively regulates $S A T B 2$ in hepatocellular 
cancer. We did not investigate mechanisms underlying the observed downregulation of SATB2 expression in ccCRC; however, published data confirm expression of miR-182 and especially miR-31 in ccRCC (34). Thus, the examination of the effects of mentioned miRs on $S A T B 2$ expression in ccRCC remains for further analysis.

Guo et al. (21) reported the correlation between low levels of SATB2 expression in ccRCC and high AJCC staging and Fuhrman grade. We did not confirm these findings; however, our study revealed the relationships between decreased nuclear SATB2 protein levels in ccRCC and greater tumor size. We demonstrated that the hazard ratio for patients whose ccRCC tissues showed reduced SATB2 immunohistochemical staining was almost three times higher than in patients with increased SATB2 immunoreactivity. Results of our investigation indicating the association of decreased SATB2 expression in tumor tissues with poor prognosis are in line with the study of Guo et al. (21). These findings support the clinical significance and tumor suppressive role of SATB2 and suggest that altered expression of SATB2 gene may promote progression of ccCRC. The relationship between downregulated $S A T B 2$ gene expression in tumor tissues and unfavorable clinicopathological parameters and prognosis was also observed in colorectal (17), laryngeal (18), non-small cell lung (19) and esophageal squamous cell (16) cancers, however, opposite results were reported for breast (13) and head and neck squamous cell (14) cancers. Thus, the role of SATB2, its expression level and association with clinical parameters is cancer-type specific.

In summary, down-regulated expression of SATB2 in ccRCC compared to non-cancerous renal tissues and correlations between decreased SATB2 expression and greater tumor size, as well as poor prognosis suggest that in ccRCC SATB2 can be considered a tumor suppressor and potential prognostic factor. Further studies are needed to explain the exact mechanisms by which SATB2 is involved in the development and progression of ccRCC.

\section{Conflicts of Interest}

The Authors declare no conflicts of interest.

\section{Acknowledgements}

This study was supported by statutory grant of University of Warmia and Mazury in Olsztyn.

\section{References}

1 Ricketts CJ and Linehan WM: Gender Specific Mutation Incidence and Survival Associations in Clear Cell Renal Cell Carcinoma (CCRCC). PLoS One 10: e0140257, 2015.

2 Rini BI, Campbell SC and Escudier B: Renal cell carcinoma. Lancet 373: 1119-1132, 2009.
3 Leibovich BC, Lohse CM, Crispen PL, Boorjian SA, Thompson $\mathrm{RH}$, Blute ML and Cheville JC: Histological subtype is an independent predictor of outcome for patients with renal cell carcinoma. J Urol 183: 1309-1315, 2010.

4 Von Roemeling CA, Marlow LA, Radisky DC, Rohl A, Larsen HE, Wei J, Sasinowska H, Zhu H, Drake R, Sasinowski M, Zhu H, Drake R, Sasinowski M, Tun HW and Copland JA: Functional genomics identifies novel genes essential for clear cell renal cell carcinoma tumor cell proliferation and migration. Oncotarget 5: 5320-5334, 2014.

5 Li C, Shu F, Lei B, Lv D, Zhang S and Mao X: Expression of PGAM1 in renal clear cell carcinoma and its clinical significance. Int J Clin Exp Pathol 8: 9410-9415, 2015.

6 Moch H, Schraml P, Bubendorf L, Mirlacher M, Kononen J, Gasser T, Mihatsch MJ, Kallioniemi OP and Sauter G: Highthroughput tissue microarray analysis to evaluate genes uncovered by cDNA microarray screening in renal cell carcinoma. Am J Pathol 154: 981-986, 1999.

7 Britanova O, Akopov S, Lukyanov S, Gruss P and Tarabykin V: Novel transcription factor Satb2 interacts with matrix attachment region DNA elements in a tissue-specific manner and demonstrates cell-type-dependent expression in the developing mouse CNS. Eur J Neurosci 21: 658-668, 2005.

8 Szemes M, Gyorgy A, Paweletz C, Dobi A and Agoston DV: Isolation and characterization of SATB2, a novel AT-rich DNA binding protein expressed in development- and cell-specific manner in the rat brain. Neurochem Res 31: 237-246, 2006.

9 Dobreva G, Chahrour M, Dautzenberg M, Chirivella L, Kanzler B, Farinas I, Karsenty $G$ and Grosschedl R: SATB2 is a multifunctional determinant of craniofacial patterning and osteoblast differentiation. Cell 125: 971-986, 2006.

10 Gyorgy AB, Szemes M, de Juan Romero C, Tarabykin V and Agoston DV: SATB2 interacts with chromatin-remodeling molecules in differentiating cortical neurons. Eur J Neurosci 27: 865-873, 2008.

11 Dobreva G, Dambacher J and Grosschedl R: SUMO modification of a novel MAR-binding protein, SATB2, modulates immunoglobulin mu gene expression. Genes Dev 17: 3048-3061, 2003.

$12 \mathrm{Yu} \mathrm{W,} \mathrm{Ma} \mathrm{Y,} \mathrm{Shankar} \mathrm{S} \mathrm{and} \mathrm{Srivastava} \mathrm{RK:} \mathrm{Role} \mathrm{of} \mathrm{SATB2} \mathrm{in}$ human pancreatic cancer: Implications in transformation and a promising biomarker. Oncotarget 7: 57783-57797, 2016.

13 Patani N, Jiang W, Mansel R, Newbold R and Mokbel K: The mRNA expression of SATB1 and SATB2 in human breast cancer. Cancer Cell Int 9: 18, 2009.

14 Chung J, Lau J, Cheng LS, Grant RI, Robinson F, Ketela T, Reis PP, Roche O, Kamel-Reid S, Moffat J, Ohh M, Perez-Ordonez B, Kaplan DR and Irwin MS: SATB2 augments $\Delta \mathrm{Np} 63 \alpha$ in head and neck squamous cell carcinoma. EMBO Rep 11: 777-783, 2010.

15 Jiang G, Cui Y, Yu X, Wu Z, Ding G and Cao L: miR-211 suppresses hepatocellular carcinoma by downregulating SATB2. Oncotarget 6: 9457-9466, 2015.

16 Geng GJ, Li N, Mi YJ, Yu XY, Luo XY, Gao J, Luo QC, Xie JD, Fa XE and Jiang J: Prognostic value of SATB2 expression in patients with esophageal squamous cell carcinoma. Int J Clin Exp Pathol 8: 423-431, 2015.

17 Wang S, Zhou J, Wang XY, Hao JM, Chen JZ, Zhang XM, Jin H, Liu L, Zhang YF, Liu J, Ding YQ and Li JM: Down-regulated expression of SATB2 is associated with metastasis and poor prognosis in colorectal cancer. J Pathol 219: 114-122, 2009. 
18 Liu TR, Xu LH, Yang AK, Zhong Q, Song M, Li MZ, Hu LJ, Chen FJ, Hu ZD, Han P and Zeng MS: Decreased expression of SATB2: a novel independent prognostic marker of worse outcome in laryngeal carcinoma patients. PLoS One 7: e40704, 2012.

19 Ma YN, Zhang HY, Fei LR, Zhang MY, Wang CC, Luo Y and Han YC: SATB2 suppresses non-small cell lung cancer invasiveness by G9a. Clin Exp Med 2017, doi: 10.1007/s10238017-0464-3 [Epub ahead of print].

20 Kucuksayan H, Ozes ON and Akca H: Downregulation of SATB2 is critical for induction of epithelial-to-mesenchymal transition and invasion of NSCLC cells. Lung Cancer 98: 122129, 2016.

21 Guo C, Xiong D, Yao X, Gu W, Zhang H, Yang B, Peng B, Liu $M$ and Zheng J: Decreased SATB2 expression is associated with metastasis and poor prognosis in human clear cell renal cell carcinoma. Int J Clin Exp Pathol 8: 3710-3718, 2015.

22 Greene FL, Page DL, Fleming ID, Fritz AG, Balch CM, Haller DG and Morrow M: AJCC Cancer Staging Manual, Sixth Edition. New York, Springer-Verlag Inc., pp. 323-334, 2002.

23 Fuhrman SA, Lasky LC and Limas C: Prognostic significance of morphologic parameters in renal cell carcinoma. Am J Surg Pathol 6: 655-663, 1982.

24 Livak KJ and Schmittgen TD: Analysis of relative gene expression data using real-time quantitative PCR and the 2(-Delta Delta C(T)) method. Methods 25: 402-408, 2001.

25 Kowalczyk AE, Godlewski J, Krazinski BE, Kiewisz J, Sliwinska-Jewsiewicka A, Kwiatkowski P, Pula B, Dziegiel P, Janiszewski J, Wierzbicki PM and Kmiec Z: Divergent expression patterns of SATB1 mRNA and SATB1 protein in colorectal cancer and normal tissues. Tumour Biol 36: 44414452, 2015.

26 Mansour MA, Hyodo T, Akter KA, Kokuryo T, Uehara K, Nagino $M$ and Senga T: SATB1 and SATB2 play opposing roles in $\mathrm{c}$-Myc expression and progression of colorectal cancer. Oncotarget 7: 4993-5006, 2016.

27 Kowalczyk AE, Krazinski BE, Godlewski J, Grzegrzolka J, Kiewisz J, Kwiatkowski P, Sliwinska-Jewsiewicka A, Dziegiel $\mathrm{P}$ and Kmiec Z: SATB1 is Down-regulated in Clear Cell Renal Cell Carcinoma and Correlates with miR-21-5p Overexpression and Poor Prognosis. Cancer Genomics Proteomics 13: 209-217, 2016.
28 Brocato J and Costa M: SATB1 and 2 in colorectal cancer. Carcinogenesis 36: 186-191, 2015.

29 Tashiro K, Teissier A, Kobayashi N, Nakanishi A, Sasaki T, Yan K, Tarabykin V, Vigier L, Sumiyama K, Hirakawa M, Nishihara $\mathrm{H}$, Pierani A and Okada N: A mammalian conserved element derived from SINE displays enhancer properties recapitulating Satb2 expression in early-born callosal projection neurons. PLoS One 6: e28497, 2011.

30 Hassan MQ, Gordon JA, Beloti MM, Croce CM, van Wijnen AJ, Stein JL, Stein GS and Lian JB: A network connecting Runx2, SATB2, and the miR-23a 27a 24-2 cluster regulates the osteoblast differentiation program. Proc Natl Acad Sci USA 107: 19879-19884, 2010.

31 Deng Y, Wu S, Zhou H, Bi X, Wang Y, Hu Y, Gu P and Fan X: Effects of a miR-31, Runx2, and Satb2 regulatory loop on the osteogenic differentiation of bone mesenchymal stem cells. Stem Cells Dev 22: 2278-2286, 2013.

32 Yang MH, Yu J, Chen N, Wang XY, Liu XY, Wang S and Ding YQ: Elevated microRNA-31 expression regulates colorectal cancer progression by repressing its target gene SATB2. PLoS One 8: e85353, 2013.

33 Yang MH, Yu J, Jiang DM, Li WL, Wang S and Ding YQ: microRNA-182 targets special AT-rich sequence-binding protein 2 to promote colorectal cancer proliferation and metastasis. $\mathbf{J}$ Transl Med 12: 109, 2014.

34 Fridman E, Dotan Z, Barshack I, David MB, Dov A, Tabak S, Zion O, Benjamin S, Benjamin H, Kuker H, Avivi C, Rosenblatt K, Polak-Charcon S, Ramon J, Rosenfeld N and Spector Y: Accurate molecular classification of renal tumors using microRNA expression. J Mol Diagn 12: 687-696, 2010 